\title{
Novel Power Quality Data Analysis and Reporting Framework for Wide-area system of registration and processing of power quality data
}

\author{
Jacek Rezmer, Zbigniew Leonowicz
}

\begin{abstract}
This paper presents a novel method for data analysis and visualization, including real-time visual monitoring and proposal for combined area $P Q$ indices on the example of the developed and operational comprehensive system of registration, archiving and data processing for the wide-area monitoring of power quality in a separated part of real power grid with distributed renewable generation. Real case studies related to power quality disturbances are presented.
\end{abstract}

Index Terms-power quality, power distribution faults, power distribution reliability, power system restoration, power system transients, relational databases, distributed generation, location of disturbances, voltage dips, GIS, data visualization and analysis.

\section{INTRODUCTION}

$\mathrm{N}$ EW ideas related to power quality data visualization and analysis are presented in this paper. One of the most important problems in assessment of power quality problems is the huge amount of different indices, numbers and information, spread in time and related to different geographical points. Aggregation and averaging leads to loss of important information.

One of the objectives of received funding was building a distributed power quality observation system. Such a system, composed of PQ monitoring units is found at the nodes of the particular distribution network, permits the study of phenomena occurring within the system containing distributed generation units. The observation system is provided with stationary time-synchronized power quality recorders with GPS synchronization. The software system supports data transmission between analyzers and database.

It permits to conduct effective analysis of phenomena occurring in a distribution system [2]. The main requirement was observation of events in networks and power facilities regardless of their location [3]. In addition, there was a requirement for synchronous data capture for quality assessment throughout PQ multi-measurements. The analysis

This work was supported by the National Science Centre (Poland) under Grant DEC-2011/01/B/ST8/02515. Manuscript published 14 Dec 2015. of the assumptions and limitations within the context of technological and economic possibilities, led to GSM telecommunications systems, permitting the best coverage of sparsely industrialized and urbanized areas.

Basic diagram of developed and realized management and measuring system is shown in Figure 1 and the system schematic is shown in Figure 2.

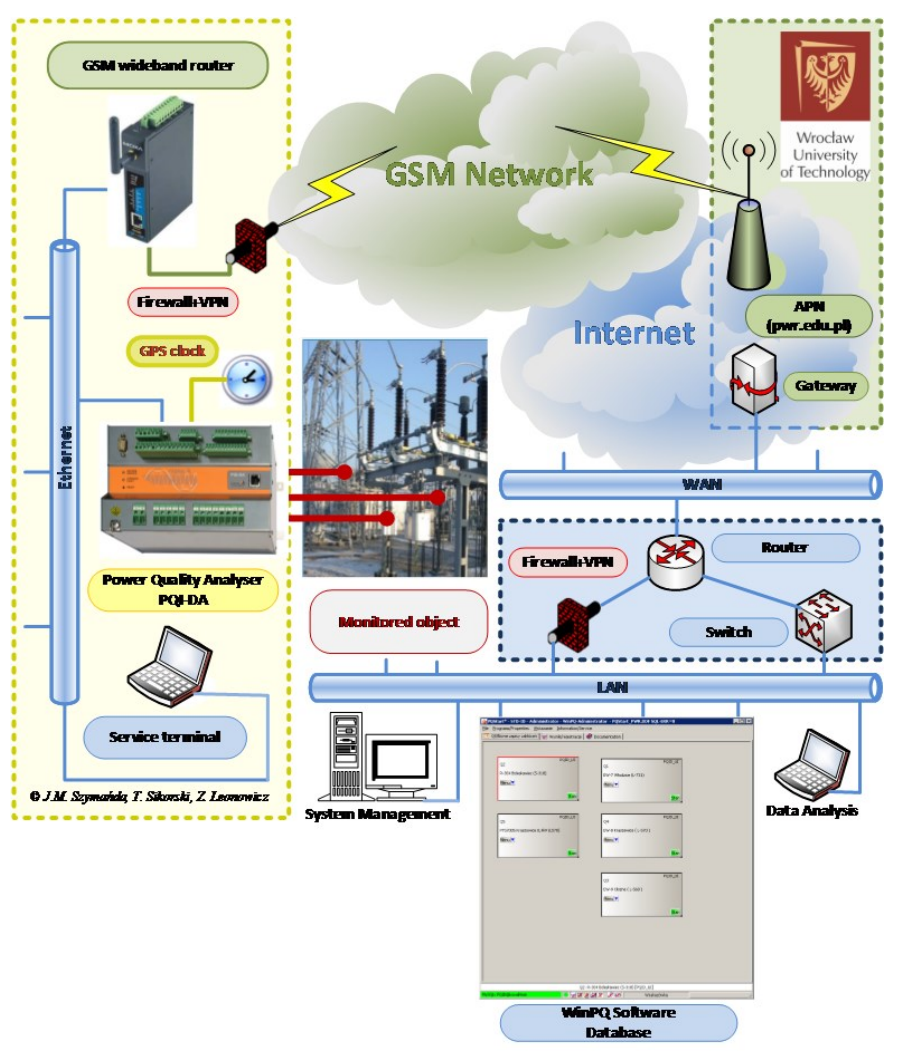

Fig. 1. Functional diagram of the wide-area PQ monitoring system $[4,5]$.

First contribution of the paper is the idea of plotting one power quality index for all nodes of the wide-area measuring system in form of radar plot, as shown in Figure 3. The second contribution is the idea of visualization of PQ data (similar to

J. Rezmer is with Wroclaw University of Technology, Poland (e-mail: jacek.rezmer@pwr.edu.pl). Z. Leonowicz is with Wroclaw University of Technology, Poland (e-mail: zbigniew.leonowicz@pwr.edu.pl). 
[1]) in form of special-purpose GIS (geographical information system), as shown in Figure 4.

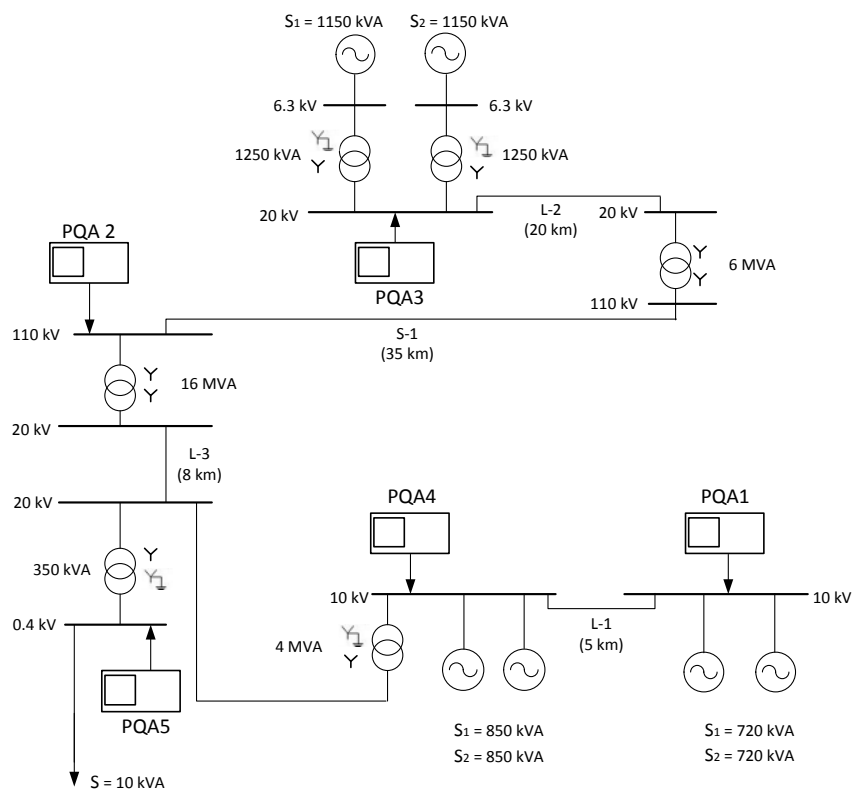

Fig. 2. Schematic of the supervised PQ monitoring system.

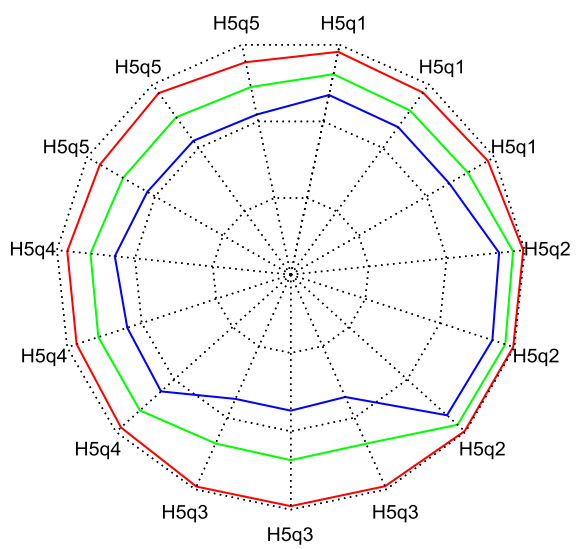

Fig. 3. Radar plot of combined PQ indices.

\section{DATA VISUALIZATION}

Radar plot (Figure 3) shows the normalized values of chosen PQ index for all nodes and phases of the system for chosen period of time (10 days in this example). Area delimited by red line shows the best PQ values for the observation period (in this example, the amplitude of $5^{\text {th }}$ harmonic as the percentage of the fundamental), scaled to the range from zero to one, where one corresponds to best power quality.

The area delimited by the polygon (with red, green or blue contour) corresponds to the whole-area PQ index. The red line corresponds to the best values, blue line to the worst values and green line to the mean values within the time period and within the area of power system. In that way one can combine multiple PQ indices into one meaningful result.

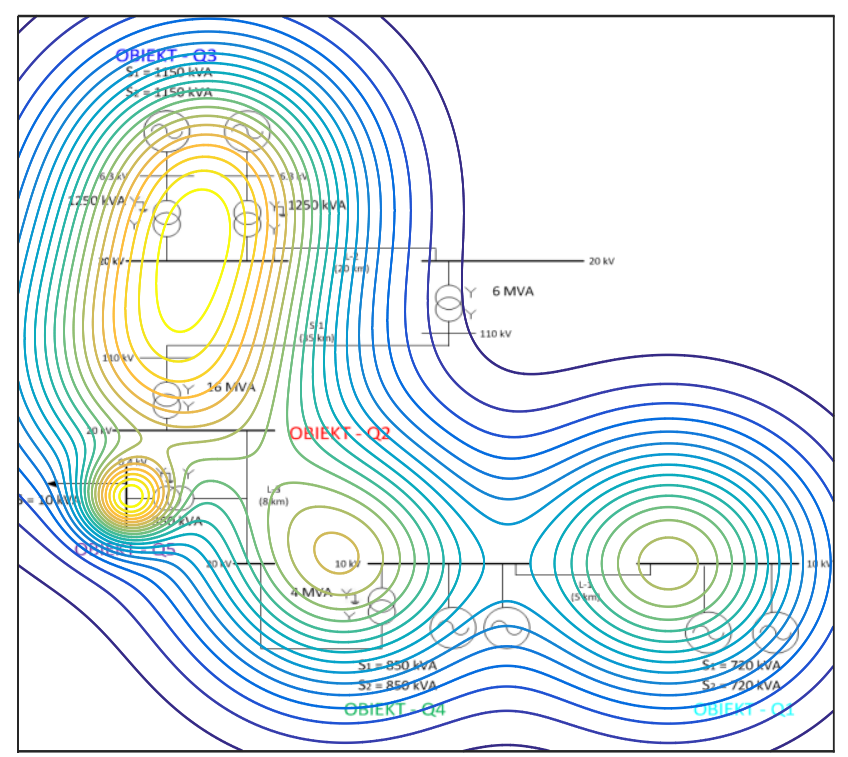

Fig. 4. GIS visualization of real-time PQ data. The figure shows one frame of the video file.

The map of PQ distribution over a geographical area is composed of the superposition of the quasi-geographical localization of the nodes of PQ monitoring system (as a map overlay) and a layer of 3-D Gaussian functions corresponding to the value of chosen index, as follows:

$$
\phi_{k}\left(t ; \mu_{k}, \sigma_{k}^{2}\right)=A \exp \left(-\frac{\left\|t-\mu_{k}\right\|^{2}}{2 \sigma_{k}^{2}}\right), k=1, \ldots, K
$$

where $A$ - amplitude is scaled by the chosen PQ index localized over the place of recording $\mu_{k}$ setting the location and $\sigma_{k}^{2}$ setting the width of the function. In the example shown in Figure 4 the $5^{\text {th }}$ harmonic level spatial distribution is shown and the width of the function corresponds to expected distance of propagation of PQ disturbance, being wider on HV level and narrower in MV and LV level.

\section{CONCLUSIONS}

In this paper two new efficient methods of power quality data for a wide area monitoring system are proposed.

Radar plot allows monitoring combined PQ indices averaged over a period of time and showing the combined PQ index as the polygon area for chosen section of the power system.

The GIS PQ visualization shows spatial and temporal distribution of PQ indices, also in real-time, allowing analysis of propagation of disturbances between nodes, mutual influence on PQ disturbances between nodes, etc.

\section{APPENDIX}

Matlab files are available on request from the authors, contact zbigniew.leonowicz@pwr.edu.pl. Video file 65,3 MB can be downloaded from: http://teee.eu/public/film3.avi. 


\section{REFERENCES}

[1] T. Cooke. Condensing PQ Data and Visualization Analytics. Presented at 2015 IEEE Power \& Energy Society General Meeting. [Online]. Available: http://www.ieepes.org/presentations/gm2015/PESGM2015P-001598.pdf

[2] P. P. Baker, T.A. Short, and C.M. Burns. "Power quality monitoring of a distribution system" IEEE Trans. on Power Delivery, Vol. 9, No. 2, , pp. 1136-1142, April 1994.

[3] A. Gubanski, P. Janik, P. Kostyla, J. Rezmer, T. Sikorski T., J. Szymanda, Z. Waclawek: "Comparative analysis of the functionality of distributed power quality monitoring systems (in Polish)". Energetyka, No 10, pp. 589-594, 2012.

[4] Z. Leonowicz, J. Rezmer, T. Sikorski, J Szymanda, P. Kostyla. Widearea system of registration and processing of power quality data in power grid with distributed generation: Part II. Localization and tracking of the sources of disturbances. 2014 14th International Conference on Environment and Electrical Engineering, EEEIC 2014 Conference Proceedings, art. no. 6835904, pp. 414-417. Available: http://ieeexplore.ieee.org/xpl/articleDetails.jsp?arnumber=6835904

[5] Z. Leonowicz, J. Rezmer, T. Sikorski, J Szymanda, P. Kostyla. Widearea system of registration and processing of power quality data in power grid with distributed generation: Part I. System description, functional tests and synchronous recordings. 2014 14th International Conference on Environment and Electrical Engineering, EEEIC 2014 Conference Proceedings, art. no. 6835904, pp. 175-181. Available: http://ieeexplore.ieee.org/xpl/articleDetails.jsp?arnumber $=6835859$

[6] R. Essomba. Smoothing Techniques using basis functions: Gaussian Basis. [Online] Available: http://datascienceplus.com/smoothingtechniques-using-basis-functions-gaussian-basis/

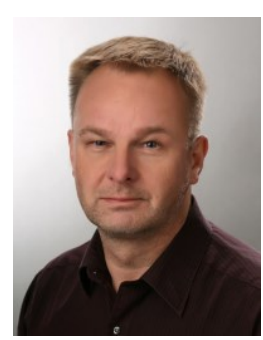

Jacek Rezmer received the M.Sc., Ph.D. and Habilitate Doctorate (Dr Sc.) degrees, all in electrical engineering, from the Wroclaw University of Technology, Poland in 1987, 1995, and 2013, respectively. He has been with the Department of Electrical Engineering, Wroclaw University of Technology, since 1987. His current research interests are in the areas of transients in power systems, control and protection, and especially application of signal processing methods in power systems.

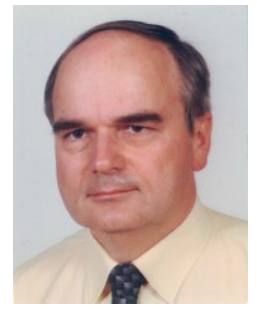

Zbigniew Leonowicz (IEEE M'03SM'12) became a Member (M) of IEEE in 2003 and a Senior Member (SM) in 2012. $\mathrm{He}$ received the M.Sc., Ph.D. and Habilitate Doctorate (Dr Sc.) degrees, all in Electrical Engineering, in 1997, 2001, and 2012, respectively. He has been with the Department of Electrical Engineering, Wroclaw University of Technology, since 1997. His current research interests are in the areas of power quality, control and protection of power systems, renewables, industrial ecology and applications of signal processing methods in power systems. 